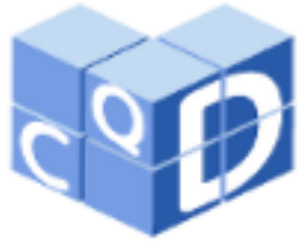

Revista Eletrônica Paulista de Matemática

ISSN 2316-9664

Volume 14, fev. 2019

Edição Ermac

Cinthia Cristhina Crotti Carrara

COC/Objetivo de Ensino

cincrotti@msn.com

Tatiana Miguel Rodrigues de Souza

UNESP - Universidade Estadual Paulista "Júlio de Mesquita Filho"

tatiana.rodrigues@unesp.br

\section{Atividade prática para o ensino de matemática financeira}

Practical activity for the teaching of financial mathematics

\section{Resumo}

Após o ensino médio espera-se que o aluno ingresse em uma faculdade, no mercado de trabalho ou provavelmente vá morar longe dos pais, tendo assim que administrar seu próprio dinheiro. Esta é uma das etapas na vida do indivíduo que a Matemática Financeira se torna uma fiel companheira, estando presente em seu cotidiano. Sendo assim, este trabalho tem como objetivo mostrar aos alunos a importância da aprendizagem da Matemática Financeira no ensino médio, bem como as vantagens de sua correta utilização na vida adulta.

Palavras-chave: Matemática Financeira. Educação Financeira. High school.

\begin{abstract}
After high school it is expected that the student will enter a college, the job market or probably go away from the parents, so he has to manage his own money. This is one of the stages in the life of the individual that Financial Mathematics becomes a faithful parachute, being present in his daily life. Thus, this paper aims to show students the importance of the learning of Financial Mathematics in high school, as well as the advantages of its correct use in adult life.
\end{abstract}

Keywords: Financial Mathematics. Financial Education. High school. 


\section{Introdução}

Para Assaf Neto (1998, p. 13) matemática financeira é o "estudo do dinheiro no tempo, ao longo do tempo". Segundo Zentgraf (2003, p. 2), além de estudar os aspectos temporais do dinheiro, tais estudos objetivam estabelecer relações entre quantias monetárias expressas em datas diferentes. Entretanto, a matemática financeira pode ser definida de forma mais simplificada sendo a aplicação da matemática para decisões gerenciais a respeito de operações financeiras. Para que as operações financeiras sejam executadas, faz-se necessário a aplicação de cálculos adequados, sendo que o estudo desses cálculos é o objeto de estudo da matemática financeira (VERAS, 2001, p. 53).

Até pouco tempo atrás, a maior parte das obras deste ramo da matemática trazia bem clara a denominação de matemática comercial e financeira. Carvalho (1971) distinguiu a matemática comercial (juros e descontos simples, ligas, moeda, câmbio e títulos de renda) da matemática financeira (juros e descontos compostos, rendas certas, empréstimos, depreciação e as tábuas financeiras).

Acredita-se que a classificação de comercial ou financeira esteja mesmo ligada à forma de resolução dos problemas. Os cálculos relacionados à utilização de fórmulas matemáticas, porcentagens, juros e descontos simples, por exemplo, estão mais próximos do conceito de comércio; os cálculos de juros compostos, séries de pagamentos, amortizações de empréstimos bancários são entendidos como financeiros, pois, em geral, utilizam-se calculadoras financeiras para a solução dos problemas apresentados.

Este artigo traz contribuições ao trabalho de Carrara e Rodrigues-Souza (2018), pois contém conceitos como porcentagem, progressão geométrica, logaritmos, juros, resultados e exemplos para melhor compreensão do leitor e, em particular, para o professor que quiser usálo como referência para a aplicação da experiência em sala de aula.

\section{Conceitos básicos}

Abaixo serão apresentados alguns conceitos que serão usados no decorrer do texto.

\subsection{Porcentagem}

A porcentagem é um dos conceitos da Matemática mais conhecidos. Podemos afirmar que é utilizada em várias outras áreas, quando queremos estimar o crescimento de algo, comparar grandezas, expressar uma quantidade de aumento ou desconto do preço de alguma mercadoria, entre outros. Trabalhamos com porcentagem o tempo todo e, mesmo quando não percebemos, estamos fazendo uso dela.

Definição: Toda razão $\frac{\mathbf{a}}{\mathbf{b}}$, na qual $\mathrm{b}=100$, chama-se porcentagem.

Ao invés do uso da expressão "por cento" usamos o símbolo \%, que significa uma divisão por 100 . Assim, 60 por cento $=60 \%=\frac{\mathbf{6 0}}{\mathbf{1 0 0}}=0,60$.

\subsection{Progressão geométrica}

Vamos analisar algumas sequências:

a) $(4,8,16,32,64)$;

CARRARA, C. C. C.; SOUZA, T. M. R. de. Atividade prática para o ensino de matemática financeira. C.Q.D.- Revista Eletrônica Paulista de Matemática, Bauru, v. 14, p. 160-169, fev. 2019. Edição Ermac. 
b) $(6,-18,54,-162)$;

c) $\left(32,8,2, \frac{\mathbf{1}}{\mathbf{2}}\right)$;

Em todas essas sequências, a lei de formação é: cada termo posterior, a partir do segundo, é igual ao anterior, multiplicado por um número fixo.

Toda sequência que tiver essa lei de formação será denominada progressão geométrica. O número fixo pelo qual estamos multiplicando cada termo é chamado razão da progressão.

A representação matemática de uma progressão geométrica (P.G.) é ( $a_{1}, a_{2}, a_{3}, \ldots, a_{n-1}$, $\left.a_{n}\right)$. Logo, temos que $a_{n+1}=a_{n} . q$, para todo $n \in \mathbb{N}^{*}$ e $q \in \mathbb{R}$.

\subsection{Logaritmos}

O logaritmo de um número real e positivo $b$, na base a, positiva e diferente de 1 , é o número $\mathrm{x}$ ao qual se deve elevar a para se obter $\mathrm{b}$.

$$
\log _{\mathbf{a}} \mathbf{b}=\mathrm{x} \quad \Leftrightarrow \quad a^{\mathrm{x}}=\mathrm{b}, \operatorname{com} \mathrm{b}>0, \mathrm{a}>0 \text { e } a \neq 1 .
$$

Na forma logarítmica, $a$ é a base do logaritmo, $b$ é o logaritmando e $x$ é o logaritmo. Já na forma exponencial, $a$ é a base da potência, $b$ é a potência e $x$ é o expoente.

Aos logaritmos que se indicam $\log _{\mathbf{a}} \mathbf{b}$ chamamos de sistemas de logaritmos de base a, e existe uma infinidade de sistemas de logaritmos. Dentre todos os sistemas, o mais importante é o sistema de logaritmos decimais, ou base 10. Indica-se: $\log _{10} \mathbf{x}$ ou $\log \mathbf{x}$.

Podemos destacar também as propriedades dos logaritmos, sendo elas:

a) Logaritmo do produto: o logaritmo de um produto é igual à soma dos logaritmos dos fatores tomados na mesma base, isto é:

Se $0<a \neq 1, b>0$ e $c>0$, então $\log _{\mathrm{a}}(\mathrm{b} . \mathrm{c})=\log _{\mathrm{a}} \mathrm{b}+\log _{\mathrm{a}} \mathrm{c}$.

b) Logaritmo do quociente: O logaritmo de um quociente é igual ao logaritmo do numerador menos o logaritmo do denominador tomados na mesma base, isto é:

Se $0<a \neq 1, b>0$ e c $>0$, então $\log _{a}(b / c)=\log _{a} b-\log _{a} c$.

c) Logaritmo da potência: O logaritmo de uma potência é igual ao produto do expoente pelo logaritmo da base da potência, isto é:

Se $0<a \neq 1, b>0$, então $\log _{\mathrm{a}}\left(\mathrm{b}^{\mathrm{n}}\right)=\mathrm{n} . \log _{\mathrm{a}} \mathrm{b}$.

\subsection{Tipos de juros} pressões:

Segundo Puccini (1993, p. 5), o conceito de juros pode ser introduzido através das exa) dinheiro pago pelo uso de dinheiro emprestado, ou seja, custo do capital de terceiros colocados à nossa disposição;

b) remuneração do capital empregado em atividades produtivas ou, ainda, remuneração paga pelas instituições financeiras sobre o capital nelas aplicado.

Os juros são fixados através de uma taxa percentual que sempre se refere a uma unidade de tempo: ano, semestre, trimestre, mês, dia.

Exemplo: $\quad 12 \%$ ao ano $=12 \%$ a.a.

$1 \%$ ao mês $=1 \%$ a. m.

A representação em porcentagem é a comumente utilizada, entretanto, todos os cálculos e desenvolvimentos de fórmulas serão feitos através da notação em fração decimal, assim podendo enfatizar o conteúdo matemático já aprendido pelos alunos. 
Os juros são normalmente classificados em simples ou compostos, dependendo do processo de cálculo utilizado.

Juros simples: Neste caso, os juros de cada período são calculados sempre em função do capital inicial empregado.

Exemplo: Um indivíduo aplicou no banco R \$200,00, e este lhe prometeu juros simples, à razão de $10 \%$ ao ano. Qual será seu saldo credor no final de cada um dos próximos quatro anos? Vejamos a tabela 1:

Tabela 1 - Crescimento de $\mathrm{R} \$ 200,00$ a juros simples de $10 \%$ a.a.

\begin{tabular}{|c|c|c|c|c|}
\hline Final do & Escala & $\begin{array}{c}\text { Saldo no início de } \\
\text { cada ano }\end{array}$ & Juros de cada ano & $\begin{array}{c}\text { Saldo no final } \\
\text { de cada ano }\end{array}$ \\
\hline- & 0 & - & - & 200,00 \\
$1^{\text {o }}$ ano & 1 & 200,00 & $0,1 \times 200,00=20,00$ & 220,00 \\
$2^{\text {o }}$ ano & 2 & 220,00 & $0,1 \times 200,00=20,00$ & 240,00 \\
$3^{\text {o }}$ ano & 3 & 240,00 & $0,1 \times 200,00=20,00$ & 260,00 \\
$4^{\text {o }}$ ano & 4 & 260,00 & $0,1 \times 200,10=20,00$ & 280,00 \\
& & & & \\
\hline
\end{tabular}

Fonte: a própria autora

Portanto, após 4 anos, segundo a tabela cima, o saldo será de R $\$ 280,00$.

Juros compostos: Nessa hipótese, os juros de cada período são calculados sempre em função do saldo existente no início do período correspondente.

Exemplo: Imagine que o mesmo indivíduo do exemplo anterior tivesse colocado os seus $\mathrm{R} \$ 200,00$ em um banco que pagasse juros compostos, à razão de $10 \%$ ao ano. Como se comportaria o seu saldo credor (composto pelos "créditos básicos", decorrentes do confronto positivo entre créditos e débitos nas operações do contribuinte) ao longo dos próximos quatro anos?

Tabela 2 - Crescimento de $\mathrm{R} \$ 200,00$ a juros compostos de $10 \%$ a.a.

\begin{tabular}{|c|c|c|c|c|}
\hline Final do & Escala & $\begin{array}{c}\text { Saldo no início de } \\
\text { cada ano }\end{array}$ & Juros de cada ano & $\begin{array}{c}\text { Saldo no final } \\
\text { de cada ano }\end{array}$ \\
\hline- & 0 & - & - & 200,00 \\
$1^{\text {o }}$ ano & 1 & 200,00 & $0,1 \times 200,00=20,00$ & 220,00 \\
$2^{\text {o }}$ ano & 2 & 220,00 & $0,1 \times 220,00=22,00$ & 242,00 \\
$3^{\text {o }}$ ano & 3 & 242,00 & $0,1 \times 242,00=24,20$ & 266,20 \\
$4^{\text {o }}$ ano & 4 & 266,20 & $0,1 \times 266,20=26,62$ & 292,82 \\
& & & & \\
\hline
\end{tabular}

Fonte: a própria autora 
Portanto, após 4 anos, segundo a tabela cima, o saldo será de $\mathrm{R} \$ 292,82$.

Ao capital inicial empregado dá-se o nome de principal, e à soma do principal mais juros dá-se o nome de montante. Assim, a juros simples apenas o capital rende juros, já a juros compostos, os rendimentos são calculados sobre os montantes, havendo assim uma incidência de juros sobre juros.

$\mathrm{O}$ mercado financeiro segue integralmente a lei de juros compostos. Entretanto, os juros simples são muito utilizados pela facilidade de cálculo e, também, como grande argumento de vendas.

\subsection{Inflação e Correção monetária}

Definição: Inflação é o aumento generalizado dos preços de bens e serviços num certo intervalo de tempo. Já a deflação é a queda generalizada dos preços. No Brasil, foram criados órgãos especializados em medir a inflação e essas medidas fornecem uma média da variação dos preços, como por exemplo o IPCA (Índice de Preços ao Consumidor) é medido mês a mês pelo IBGE (Instituto Brasileiro de Geografia e Estatística), entre outros. Em particular, o Banco Central considera o IPCA como o índice brasileiro oficial da inflação ou deflação.

É importante, antes de selecionar um índice para atualização de uma série de valores monetários, provir-se a uma análise de sua representatividade em relação aos propósitos em consideração (ASSAF, 1998).

Para atualizar monetariamente uma importância afetada pela inflação, usamos o mesmo raciocínio desenvolvido em juros compostos.

De acordo com Dornbusch e Fischer (2006), a inflação é impopular, visto que os produtos que as pessoas estão comprando estão aumentando. A impopularidade da inflação se mantém mesmo se as rendas das pessoas aumentarem proporcionalmente aos preços. Ela está relacionada a diferentes distúrbios econômicos, como o choque dos preços de petróleo da década de 60 .

Com a finalidade da atualização dos preços, provocada pela inflação, foi institucionalizada no Brasil, no período de outubro de 1964 a fevereiro de 1986, a aplicação da correção monetária. A atualização dos preços era feita mensal, trimestral ou anualmente, bastando multiplicar o preço antigo pelo fator de atualização $1+f$, em que $f$ era a taxa unitária da inflação verificada no respectivo período. Sendo assim, a correção monetária nada mais é do que o reajuste dos capitais envolvidos em operações financeiras, com o objetivo de anular, ou pelo menos atenuar, os efeitos da inflação.

O índice utilizado para a aplicação da correção monetária era o da variação das Obrigações Reajustáveis do Tesouro Nacional (ORTN), que, depois, passaram a ser denominadas Obrigações do Tesouro Nacional (OTN), também conhecidos como indexador.

\subsection{Amortização}

Definição: Amortização é um processo de extinção de uma dívida através de pagamentos periódicos, que são realizados em função de um planejamento, de modo que cada prestação corresponde à soma do reembolso do Capital ou do pagamento dos juros do saldo devedor, 
podendo ser o reembolso de ambos, sendo que os juros sempre são calculados sobre o saldo devedor.

No pagamento de dívidas, a juros compostos, cada parcela de pagamento pode incluir:

a) juros do período, calculados sobre o saldo da dívida no início do período;

b) amortização do principal, correspondente ao pagamento parcial (ou integral) do principal.

Os principais sistemas de amortização são: Sistema de Pagamentos variáveis; Sistema Americano; Sistema de Pagamento único; Sistema de Amortização Constante (SAC); Sistema Price ou Francês (PRICE); Sistema de Amortização Misto (SAM); Sistema Alemão. Em todos os sistemas de amortização, cada pagamento é a soma do valor amortizado com os juros do saldo devedor.

\section{Sistema Price}

No método Price, o financiamento é pago em prestações mensais iguais, cada uma sendo subdividida em duas parcelas: juros do período, calculados sobre o saldo no início do período; e amortização do principal, obtida pela diferença entre o valor de prestação e o valor de juros do período.

A utilização desse sistema é bastante difundida, cabendo ressaltar as aplicações como: financiamentos imobiliários e Crédito Direto ao Consumidor.

\section{Sistema de Amortizações Constantes (SAC)}

Para o caso do SAC, o financiamento é pago em prestações uniformemente decrescentes, cada uma sendo subdividida em duas parcelas: juros do período, calculados sobre o saldo no início do período; e amortização do principal, obtida pela divisão do principal pelo número total de prestações.

A relação prestação $=$ amortização + juros continua válida, entretanto, a ordem de obtenção das parcelas passou a ser:

a) cálculo da amortização do principal, que tem valor constante em todas as prestações, através da divisão do principal pelo número de prestações;

b) cálculo dos juros do período, pela aplicação da taxa do contrato sobre o valor do saldo (principal remanescente) no início do período;

c) cálculo do valor da prestação pela soma da amortização do principal com os juros do período.

Esse sistema também é conhecido como Método Hamburguês, e tem grande aplicação em financiamentos imobiliários e financiamento às empresas, por parte de várias entidades governamentais.

\section{Atividade prática}

A atividade prática relacionada ao tema foi aplicada na escola particular Colégio "Max Beny Macena", Sistema COC de Ensino, localizada na cidade de Bariri, interior de São Paulo, e teve duração de três meses. As séries escolhidas foram $2^{\mathrm{a}}$ e $3^{\mathrm{a}}$ séries do Ensino Médio, tendo em vista que os alunos já conheciam os conceitos de juros simples e compostos, introdução à matemática financeira e progressão geométrica.

O objetivo foi mostrar aos alunos de um modo prático o rendimento de uma caderneta de poupança ou de um investimento, como por exemplo o L.C.I. (Letras de Crédito Imobiliário), 
na vida real. Sendo assim, conscientizá-los sobre a melhor aplicação de um capital e o tempo necessário para alcançar o montante desejado, como também incentivá-los a organizar e conscientizar sobre suas finanças e objetivos.

Para os alunos da $2^{\mathrm{a}}$ série do ensino médio foi solicitado que estipulassem uma quantia em reais que fosse suficiente para realizar um sonho ou uma vontade, como por exemplo uma viagem, um videogame, entre outros. Já para os alunos da $3^{\mathrm{a}}$ série do ensino médio foi solicitado o curso de uma faculdade particular que gostariam de fazer e um carro para adquirir, que seriam aspirações dos jovens nesta faixa etária.

Diariamente os alunos estavam expostos a regras pré-estabelecidas que lhes permitiam "ganhar ou perder" dinheiro, este obtido através da soma de suas médias na disciplina de Matemática referentes ao primeiro e segundo bimestre. Assim, perante suas atitudes e atividades eles creditavam ou debitavam percentuais de seus valores através de uma planilha de controle (Figura 1). Essa planilha foi preenchida semanalmente durante três meses.

Após a coleta dos dados e explicação das regras aos alunos, foram revisados conceitos necessários para a realização da atividade, sendo esses: porcentagem (diferentes formas), juros simples e juros compostos. Abordados de uma maneira simples através de exemplos do cotidiano, tais como desvalorização de um automóvel ao longo dos anos, empréstimo bancário e desconto em boletos de cobrança, os alunos interagiram e puderam vivenciar a importância da organização financeira na prática. Também foi explicado o significado de uma caderneta de poupança e um investimento, seus diferentes rendimentos e riscos.

Cada aluno optou por um tipo de investimento, entre poupança (rendimento mensal de $0,5 \%$ ) e L.C.I. (rendimento trimestral de 1,6\%). Em sua totalidade, os alunos da $3^{\mathrm{a}}$ série do ensino médio não podendo arriscar optaram pelo investimento em poupança. Dos alunos da $2^{\mathrm{a}}$ série do ensino médio, $12 \%$ optaram pelo L.C.I.

Para crédito inicial foi considerada a soma das notas do $1^{\circ}$ e do $2^{\circ}$ bimestre de cada aluno na disciplina de Matemática. No caso do $2^{\circ}$ ano esta soma foi multiplicada por 50 , e do $3^{\circ}$ ano, multiplicada por 1.000 devido aos seus valores serem mais altos. Considerando as ações dos alunos ao longo de três meses, estes chegavam mais perto ou não de alcançar seus objetivos com o passar dos dias, e percebiam a dificuldade em alcançar o montante desejado com rendimentos baixos e débitos constantes em alguns casos.

No $2^{\circ}$ ano o valor a ser alcançado foi estipulado pelos próprios alunos. Já no $3^{\circ}$ ano foi calculado da seguinte maneira: valor de $50 \%$ da mensalidade (FIES) da faculdade particular que optaram, durante toda a extensão do curso, mais o valor do carro que gostariam de adquirir.

A atividade teve início no dia 15 de agosto e término no dia 15 de novembro, com alguns alunos atingindo seus objetivos e outros não. 
Nome: Victólua Capone furcun;

Folha: $\underline{01}$

Objetivo: viajar vara Itáluai

Valor Inicial: R R50,00 Valor esperado: R $\$ 6.000,00$

Poupança/ Investimento: Paupenças

Taxa: $0,5 \%$

\begin{tabular}{|c|c|c|c|c|}
\hline DATA & DESCRIÇÄO & TAXA (\%) & C/D & SALDO \\
\hline $01 / 08$ & Valor inicial & -- & -- & $850,00 \mathrm{C}$ \\
\hline 18108 & Comportamento & 2,5 & C & $871,25 \mathrm{C}$ \\
\hline 21108 & Tarefan & 5 & c & $914,81255 \mathrm{C}$ \\
\hline 22108 & Tarefa & 5 & C & $960,55312 \mathrm{C}$ \\
\hline 24108 & Terefa & 5 & C & $1008,5807 \mathrm{C}$ \\
\hline 25108 & Comportamento & 2,5 & c & $1033,7952 \mathrm{C}$ \\
\hline 28108 & Terefa & 5 & C & Do85 $4849 \mathrm{C}$ \\
\hline 0109 & Comportimento & 2,5 & C & $1112,622,0$ \\
\hline $06 / 09$ & Comportamento & 2,5 & C & $1140,43755 \mathrm{C}$ \\
\hline 12109 & Tarefas & 5 & $D$ & $108344567 \mathrm{C}$ \\
\hline 12109 & Terefe & 5 & $D$ & $102,9,24489 \mathrm{C}$ \\
\hline 14109 & Comportamento & 5 & C & $1080,70713 \mathrm{C}$ \\
\hline 18109 & Rendimrento de poupenca. & 0,5 & c & $1086,11067 \mathrm{C}$ \\
\hline 18109 & Terefa & 5 & C & $1.540,4162 c$ \\
\hline 220109 & Compurtamento & 25 & C & $1168,92661 \mathrm{C}$ \\
\hline 25109 & Tarefa & 5 & C & $1227,37294 \mathrm{C}$ \\
\hline 26109 & Tarefa & 5 & C & $1288,74159 \mathrm{C}$ \\
\hline 2609 & Bac matemática (3 Birrestre) & $3,7 \%$ & C & $1336,42503 C$ \\
\hline 02110 & Tarefa & 5 & C & $1403,24628 \mathrm{C}$ \\
\hline 02110 & Terefan & 5 & C & $1473,40859 \mathrm{C}$ \\
\hline $04 / 100$ & Comportamento & 2,5 & $c$ & $1510,24381 C$ \\
\hline $04 / 10$ & Laborztório Biologia (3 Birmestre) & 2,25 & C & 1544,22420 \\
\hline 04110 & AN (3-Bimestre) & $4 \%$ & $c$ & $1605,9931 \mathrm{C}$ \\
\hline $04 / 10$ & Depósito $\rightarrow$ mrédia mat $(3 \mathrm{Bim})$ & $(425,00)$ & C & $2030,9931 \mathrm{c}$ \\
\hline $06 / 10$ & Comportamento & 2,5 & c & $2081,7679 c$ \\
\hline $09 / 10$ & Tarefe & 5 & C & $2185,8562 c$ \\
\hline $11 / 10$ & Comportamento & 2,5 & C & $22,40,5026 \mathrm{C}$ \\
\hline $16 / \$ 0$ & Tarefe & 5 & C & $2352,52,77 c$ \\
\hline 16110 & Atraso & 2,5 & D & $2,350,0277 c$ \\
\hline $20 / 10$ & Comportzmento & 2,5 & C & $2408,7783 c$ \\
\hline $20 / 10$ & Prendimento de poupancz & 0,5 & C & 2420,82210 \\
\hline 241.10 & Tarefa & 5 & $C$ & $2541,8632 \mathrm{C}$ \\
\hline $27 / 10$ & Comportamento & 2,5 & C & $2668,9563 c$ \\
\hline $30 / 10$ & Terefe & 5 & C & $2802,4041 c$ \\
\hline $3 \Delta 110$ & Parefe & 5 & C & $2942,5243 c$ \\
\hline $1 / 11$ & Comportemento & 2,5 & c & $3016,0874 c$ \\
\hline $9 / 11$ & Terefa & 5 & $D$ & $28652831 C$ \\
\hline $10 / 11$ & Comportamente & 2,5 & $\mathrm{C}$ & 2936,91510 \\
\hline $17 / 11$ & Comportzmento & 2,5 & c & 3010,33790 \\
\hline $16 / 11$ & Rrendimento de poupanç & 0,5 & C & $3025,3895 \mathrm{C}$ \\
\hline & & & & \\
\hline & & & & \\
\hline
\end{tabular}

Figura 1 - Planilha de uma aluna do $3^{\circ}$ ano do Ensino Médio

\section{Resultados e discussões}

CARRARA, C. C. C.; SOUZA, T. M. R. de. Atividade prática para o ensino de matemática financeira. C.Q.D.- Revista Eletrônica Paulista de Matemática, Bauru, v. 14, p. 160-169, fev. 2019. Edição Ermac.

DOI: 10.21167/cqdvol14ermac201923169664cccctmrs160169 Disponível em: https://www.fc.unesp.br/\#!/departamentos/matematica/revista-cqd/ 
Podemos concluir com o término do projeto que os alunos adquiriram um conhecimento real de como seria trabalhar e administrar suas finanças quando assim fosse necessário. De uma maneira simples, porém divertida, eles mergulharam no mundo da economia, vivenciaram situações problemas que enfrentariam em suas vidas e concretizaram conceitos importantes, que não só os auxiliaram em sua formação acadêmica, como também em seus papéis como cidadãos.

\section{Conclusões}

A abordagem da matemática financeira através da atividade prática fez com que os alunos pudessem resgatar seus entusiasmos pela disciplina e ver a aplicabilidade da matemática, na qual esta, apesar de muito abstrata, ser constantemente empregada no dia-a-dia. Todo tipo de mudança proporciona ao aluno curiosidade e, consequentemente, um melhor entendimento do conteúdo, sendo esses objetivos os principais alcançados aqui.

Finalizamos este trabalho com uma citação do brilhante filósofo e educador Paulo Freire: "A teoria sem a prática vira "verbalismo", assim como a prática sem teoria vira ativismo. No entanto, quando se une a prática com a teoria tem-se a práxis, a ação criadora e modificadora da realidade."

\section{Referências}

ASSAF NETO, Alexandre. Matemática financeira e suas aplicações. 4. ed. São Paulo: Atlas, 1998.

CARRARA, Cinthia Cristhina Crotti; RODRIGUES-SOUZA, Tatiana Miguel. Atividade prática para o ensino de matemática financeira no ensino médio. In: ENCONTRO REGIONAL DE MATEMÁTICA APLICADA E COMPUTACIONAL, 5., 2018, Bauru. Caderno de trabalhos e resumos... Bauru: Unesp, Faculdade de Ciências, 2018. p. 85-89. Disponível em: $<$ https://www.fc.unesp.br/\#!/departamentos/matematica/eventos2341/ermac-2018/caderno-de-

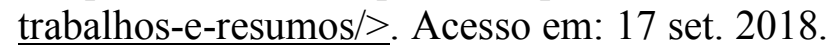

CARVALHO, Thales Mello. Matemática comercial e financeira: complementos de matemática. 2. ed., rev. e atual. Rio de Janeiro: Fename, 1971.

D'AMBRÓSIO, Nicolau; D'AMBRÓSIO, Ubiratan. Matemática comercial e financeira e complementos de matemática para os cursos do 2. grau. 23. ed. São Paulo: Companhia Nacional, 1975.

DORNBUSCH, Rudiger; FISCHER, Stanley. Macroeconomia. 5. ed. São Paulo: Makron Books, 2006.

FRANCISCO, Walter de. Matemática financeira. 6. ed. São Paulo: Atlas, 1988.

GIOVANNI, José Ruy; BONJORNO, José Roberto; GIOVANNI JUNIOR, José Ruy. Matemática completa: ensino médio. São Paulo: FTD, 2002. 
HAZZAN, Samuel. Matemática financeira. 6. ed. São Paulo: Saraiva, 2007.

IFRAH, Georges. História universal dos algarismos: a inteligência dos homens contada pelos números e pelo cálculo. Rio de Janeiro: Nova Fronteira, 1997. Tomo I.

PARENTE, Eduardo Afonso de Medeiros; CARIBE, Roberto. Matemática comercial e financeira. São Paulo: FTD, 1996.

OECD handbook on economic globalisation indicators. Paris: OECD, 2005.

PUCCINI, Abelardo de Lima. Matemática financeira: objetiva e aplicada. 5. ed. São Paulo: LTC, 1993.

VERAS, Lilia Ladeira. Matemática financeira: uso de calculadoras financeiras, aplicações ao mercado financeiro, introdução à engenharia econômica, 300 exercícios resolvidos e propostos com respostas. 4. ed. São Paulo: Atlas, 2001.

ZENTGRAF, Roberto. Matemática financeira objetiva. 4. ed. Rio de Janeiro: ZTG, 2003. 